\title{
A DISCUSSION OF HEALTHCARE SUPPORT FOR ADOLESCENTS AND YOUNG ADULTS WITH LONG TERM CONDITIONS: CURRENT POLICY AND PRACTICE, AND FUTURE OPPORTUNITIES
}

\author{
RUNNING TITLE \\ Supporting adolescents and young adults
}

\author{
AUTHORS \\ - Dr Steven JAMES RN, PhD \\ School of Nursing, Midwifery and Paramedicine \\ University of the Sunshine Coast \\ Caboolture, Queensland, Australia \\ - Prof Lin PERRY RN, MSc, PhD \\ Faculty of Health \\ University of Technology Sydney \\ Ultimo, New South Wales, Australia \\ South Eastern Sydney Local Health District \\ Prince of Wales Hospital \\ Randwick, New South Wales, Australia
}

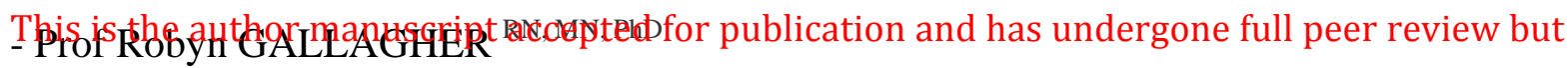
has not been through the copyediting, typesetting, pagination and proofreading process, which Glagrlesdexkdirffecemtes between this version and the Version of Record. Please cite this article as doi: 10.1111/ijn.12882

This article is protected by copyright. All rights reserved. 
University of Sydney

Sydney, New South Wales, Australia

- Assoc. Prof Julia LOWE MBChB FRCP MMedSci

Faculty of Health and Medicine

University of Newcastle

Callaghan, New South Wales, Australia

\section{CORRESPONDING AUTHOR}

- Dr Steven James

School of Nursing, Midwifery and Paramedicine

University of the Sunshine Coast

Caboolture, Queensland, Australia

Email: sjames1@usc.edu.au

Telephone: +61 754302929

\section{ACKNOWLEDGEMENTS}

This work was supported by an Australian Government Research Training Program Scholarship $(\mathrm{PhD}$, University of Technology Sydney - SJ)

\section{CONFLICTS OF INTEREST}

The authors declare no conflicts of interest 


\section{AUTHORS' CONTRIBUTIONS}

All listed authors meet the authorship criteria, prepared and agreed the content of the manuscript 


\begin{abstract}
Background: Adolescence and young adulthood can be a period of significant and unique life changes in which competing demands and challenges distract from disease self-management. Specific challenges related to the way individual services are configured can also limit the support available. This paper presents a discussion of healthcare service support for adolescents and young adults, using type 1 diabetes as an exemplar.
\end{abstract}

Design: Discussion paper.

Discussion: A wide variety of issues at the bio-psycho-social level of the individual, health services policy and practice pose challenges to effective health support for adolescents and young adults. Inter-sectoral, multi-level and multi-component opportunities are available to engage and empower young people to be part of change and accountability mechanisms, and to transform the support available and outcomes achievable. A priority research agenda can benefit patients, families and their communities.

Conclusion: Future policy and practice development may assist clinicians, service providers and managers, policymakers, non-governmental organisations and community groups to deliver more effective and efficient support to vulnerable adolescent and young adult populations. 


\section{SUMMARY STATEMENTS}

What is already known about the topic?

- Multiple issues affecting adolescents and young adults can deter self-management and contribute to deterioration in health in young adults.

- In young people with chronic conditions such as type 1 diabetes, this can accelerate onset of disease complications and co-morbidities.

- Current service models often fail to acknowledge or address the unique needs of this population.

\section{What this paper adds:}

- Adolescents and young adults need age-specific services co-designed to engage and empower, staffed with clinicians with expertise in relevant communication as well as clinical skills.

- New technologies should be adopted to address the challenges of provision of specialist services over distance, providing remote teleconference support for both patients and clinicians.

- Expanded national clinical guidelines and standards will support clinicians and promote equity in service delivery.

The implications of this paper:

- Without service innovation, the deterioration in health seen in young adults with chronic conditions as they transition from childhood to adulthood will continue, wasting the gains accrued in recent decades with the focus on children's services.

- Greater transparency and use of clinical indicator data can inform and support service planning in line with community needs. 
- Greater alignment of services to the needs of adolescents and young adults, and greater support for clinicians in meeting these, offer opportunities for both improved young adult outcomes and better staff satisfaction and retention.

\begin{abstract}
KEYWORDS
Adolescents; Young adults; Health services; Nurses; Diabetes mellitus, Type 1.
\end{abstract}

\title{
THE WICKED PROBLEM OF ADOLESCENT AND YOUNG ADULT HEALTHCARE
}

Young adulthood can be a period of significant and unique physiological, psychological and social upheaval (Arnett, 2004). The challenges experienced during this life transition, of becoming a mature adult, may distract adolescents and young adults with long-term conditions from effective self-management of their disease. Engagement with healthcare services, essential to support management and early detection of complications of diseases such as diabetes, for treatment initiation, regular monitoring and secondary prevention, has been reported as inconsistent internationally (Hynes et al., 2014; James et al., 2014b). High rates of unplanned healthcare contacts have been recorded for many, commonly, in diabetes, for uncontrolled blood glucose (James et al., 2014b; Perry et al., 2017; Redberg, 2014). Risks for premature morbidity and mortality are consequently increased (American Diabetes Association, 2011; James et al., 2014a).

Australia offers a wide range of opportunities for service improvement, many of which might also be relevant to consider elsewhere. It offers opportunities for change in healthcare systems around models of transition and transition preparation; in adult-based models of care; in primary care; in communication and healthcare technologies; and in specialist expertise to better enable such support. Changes to state and national healthcare policy could also facilitate patient-centred

This article is protected by copyright. All rights reserved. 
data-sharing, to enable national quality monitoring including of access to subsidised diabetesrelated supplies as well as service uptake.

\section{Healthcare systems}

\section{Transition preparation}

Healthcare systems for children and adults are administered separately and employ different models of care; the responsibility for managing the transition between them is seldom clearly defined. Not surprisingly, paediatric and adult systems differ significantly in their approach and provision of healthcare. In paediatric services, consultations and management approaches tend to be holistic, with an emphasis on behavioural and developmental issues. Treatment goals are commonly developed and monitored in a manner that acknowledges the complex interplay of physical, psycho-emotional and social influences of home, school and social worlds; parents/guardians are typically included. However, paediatric services and family-centred care tend to become increasingly unsuitable for adolescents in view of their increasing desire for independence.

In contrast, consultations in adult care tend to be of shorter duration, typically focus predominantly on medical issues and avoidance of future complications. There is an expectation that patients will make rational decisions and take responsibility for mature individual behaviour, treatment and health information access choices (American Diabetes Association, 2011). However, decision-making during adolescence and young adulthood is not always futureoriented and logical, as illustrated by the health risking behaviours that can be a feature of the age. Ongoing neurocognitive development of the brain's pre-frontal cortex also means that executive function capacity remains immature often into the mid-twenties, with significant 
implications for self-management (Blakemore \& Choudhury, 2006). The assumptions of adult service providers and their adolescent and young adult patients may therefore be mismatched, and hence may serve young people poorly (Australian Type 1 Diabetes Guidelines Expert Advisory Group, 2011; Nakhla et al., 2017).

The importance of this transition period has been flagged internationally through, for example, a United Nations General Comment (American Diabetes Association, 2011; Patton et al., 2016; United Nations Human Rights, 2019). A comprehensive age-specific program to manage the transition process to adult-based healthcare may be a solution to afford young adults the knowledge and skills they need for informed health decision-making around disease selfmanagement behaviours, problem solving and active collaboration with the healthcare team (American Diabetes Association, 2011; Perry et al., 2010).

There is international agreement that the transition process of adolescents and young adults with type 1 diabetes (AYAT1D) from paediatric to adult-based diabetes healthcare systems should occur in a purposeful, structured and collaborative manner (American Diabetes Association, 2011; Australian Type 1 Diabetes Guidelines Expert Advisory Group, 2011; New South Wales Agency For Clinical Innovation, 2013). Structured transition programs, consisting of procedures and guidelines to help patients prepare and transfer to adult care, have been shown to result in better outcomes than unstructured transfers, including lower HbA1c at first adult visit, fewer acute and chronic complications, and less loss to follow-up care (Garvey et al., 2012; Lane et al., 2007; Logan et al., 2008). However, few diabetes services conduct or evaluate transition in a systematic and rigorous fashion (Campbell et al., 2016; Hynes et al., 2014). The challenges in bridging two separate health models of care and two distinct busy healthcare services have been described for numerous diseases (McDonagh \& Viner, 2006). In Australia in 2011, only 26\% of 
young adults (aged 18-24 years) with type 1 or type 2 diabetes reported knowing to which adult diabetes healthcare service they were being transferred, and almost half (49\%) had never discussed transition from a paediatric to adult diabetes service with a healthcare professional (HCP) (Diabetes Australia, 2012).

\section{Transition preparation models}

Healthcare services need guidance in delivering transition support; to facilitate formulation and implementation of local policies and procedures to translate guidelines into practice, to improve transition readiness. Establishment of service standards could improve equity of access across this patient population. In Australia and Europe, exemplar diabetes models (the 'Sweet Diabetes Transition Program'(Bowden et al., 2009; Sequeira et al., 2015) and SWEET: 'Better control in paediatric and adolescent diabeteS: Working to crEate cEnTers of reference' (Danne et al., 2012)) of transition services have been configured to meet local needs. Key components of the models include multi-disciplinary HCPs with diabetes expertise, timing flexibility, assignment of a transition case worker, choice of adult diabetes healthcare provider, and substantial preparation and coordination, with young people involved in directing the transition process (Patton et al., 2016). After-hours crisis support is crucial (Farrell \& Holmes-Walker, 2011; Government of Western Australia, 2019; Victorian Government, 2018), and might prove cost-neutral or even cost-saving. $\mathrm{HCP}$ training standards and service accreditation are important considerations, and electronic health records facilitate cross-service communication and longitudinal evaluation.

\section{Adult-based models of care}

Mismatched assumptions of adult service providers and their young patients may result in young adults coming to be regarded as 'difficult' or 'non-compliant' patients. Addressing their needs is too often relegated to the 'too hard' basket' Few potential solutions have been proposed (James 
et al., 2016a, 2016b; Perry et al., 2012) and there is little evidence of effectiveness for interventions in adult-based services at improving clinical, behavioural and psychosocial outcomes amongst AYAT1D (O'Hara et al., 2017). Young adults seek open communication and care coordination from their healthcare providers. They want improved access to ageappropriate, less fragmented and better coordinated healthcare, and greater psychosocial support (Diabetes Australia, 2006; Perry et al., 2012).

Internationally, this is compounded where adolescents and young adults with specialist service needs, such as those with diabetes, live in regional and rural geographical areas. They are often doubly disadvantaged by the scarcity of local specialist healthcare and the travel needed to access it, especially when HCPs exclusively deliver services by conventional consultation. Other limiting factors include transport availability and service operational hours (Birch et al., 2008; Kibbey et al., 2013; $\mathrm{Ng}$ et al., 2017). If young people are unable to access support and direction from appropriately knowledgeable HCPs they have little option but to manage by themselves, seeking advice from whatever source is available to them regardless of quality (James, 2017). This presents an important research priority: to determine new services that will be appropriate and acceptable for AYAT1D, feasible and workable for service providers and achieve efficient, effective and cost-effective outcomes for patients, providers and the community.

\section{Primary care}

Primary care can play a pivotal role for young people as an important point of continuity across the lifespan, and as they transition from paediatric to adult diabetes services (American Diabetes Association, 2011; Australian Type 1 Diabetes Guidelines Expert Advisory Group, 2011). It is generally assumed that primary care has a greater role and responsibility for healthcare provision where there is no locally-accessible adult specialist diabetes service (Australian Type 1 Diabetes 
Guidelines Expert Advisory Group, 2011), but there is little evidence whether or when this happens. Data are lacking on whether Australians access multiple primary care providers to, for example, manage appointment waiting times, but overseas it has been reported that around $14 \%$ of patients with diabetes 'doctor shop' (Agrawal et al., 2016). AYAT1D may also access multiple HCPs because they are often geographically mobile (Agrawal et al., 2016), which presents a major obstacle to the provision of continuity of care.

Despite the imperative of doing so, it is unclear how AYAT1D, who often move between parental home, work, college and university, may be encouraged to maintain contact with a single practice. Financial incentives for practices have had minimal or no effect on patient engagement or clinical outcomes (Latham \& Gard Marshall, 2015). Good relationships with healthcare providers are generally thought to sustain engagement, but better understanding is required of young people's primary care choices and how these may be optimised.

\section{Communication technologies}

Communication technologies may promote engagement of young people with specialist health services. Increasing use of videoconferencing using personal communication software such as Skype $^{\mathrm{TM}}$ and Facetime ${ }^{\circledR}$, as well as commercial systems managed by healthcare organisations, is available to facilitate health systems to be more flexible and responsive, and enable targeted care in real time. Video-conferencing has been the means through which young people have reengaged with specialist diabetes healthcare services (Dunbabin et al., 2015), and can be utilised at relatively low cost. Despite some concerns about the security of healthcare support provided using personal communication software, there is no evidence that such software is unsuitable for clinical use. Many purpose-developed secure platforms are also available, as are other forms of 
communication technologies such as social networking sites, email, short and multi-media messaging services.

Use of communication technologies requires some adjustments from health systems. For example, provision of equipment to staff members, organisation at locations where the electronic access will physically occur, and nomination of local support in achieving the objectives agreed in consultations. With an estimated $95 \%$ of undergraduate students owning a laptop or smartphone (Pomerantz \& Brooks, 2017), communication technologies may be highly suitable. Technologies also offer opportunities for peer support and professional development amongst HCPs; particularly important where collegial support is otherwise lacking. Effective self-management increasingly involves new technologies, particularly in support of self-monitoring and communication with HCPs. These are often in the form of specialised program applications (“apps”) (Australian Communications and Media Authority, 2013; James et al., 2016a). Downloaded on smart phones and tablets, apps can track personal data such as respiratory function; can provide timely information on, for example, carbohydrate content of foods (James et al., 2016a), and reminders of appointments. They can electronically transfer data e.g. blood pressure, spirometry, weight, blood glucose measurements, to HCPs.

\section{Specialist expertise}

Maintaining up to date knowledge of apps, a fast-moving field, poses challenges for HCPs. Support is needed to develop and maintain the expertise required by HCPs to provide care for patients with specialist needs. Particularly in relation to the use of new technologies for glucose monitoring and insulin delivery, diabetes offers a particularly pertinent and well-demonstrated, although not well addressed, case. Consensus guidelines for continuous subcutaneous insulin infusion (CSII) use highlight the need for involvement of a skilled multi-disciplinary healthcare 
team (Grunberger et al., 2014; The Australian National Adult Insulin Pump Therapy Working Group, 2013), but there is no stipulation or consensus as to the level of expertise required, or how this may be attained. If standards are defined then HCPs will need support and ongoing education to attain and maintain their skills and currency, an issue in many settings (James et al., 2016b). As knowledge deficits, lack of competence and confidence in HCPs have been identified as barriers to accessing expert support (James et al., 2016a), innovative approaches are required to upskill and maintain currency. Continuing education and support has been reported to result in positive practice changes amongst diabetes specialist and generalist HCPs working in rural and remote areas (Giles et al., 2009).

Deficits in diabetes knowledge and lack of organisational support to remedy this are not unique to diabetes educators. Wide-spread serious and sustained deficiencies in nurses' diabetes-related knowledge have been reported globally (Alotaibi et al., 2016), which has implications for AYAT1D when they present to emergency departments or are hospitalised. Diabetes HCPs should be consulted on educational approaches that would be most useful and acceptable. Rotating clinical placements across and between paediatric and adult diabetes care settings could assist in improving HCPs' expertise in use of common diabetes-related technologies, as these are more commonly used for children and in paediatric healthcare settings (James et al., 2016a). National professional associations can play a key role with successful strategies including promoting mentorship through member mentoring programs (Australian Diabetes Educators Association) and periodic detailed summaries of research findings and evolving technologies to help members keep up to date (James et al., 2016b). Continuing education through use of communication technologies and online modules could support attainment and retention of credentialed or certified diabetes educator status (Australian Diabetes Educators Association, 
2019) and could enhance the knowledge of those providing services to people with type 1 diabetes.

\section{Healthcare policy}

\section{Patient-centred data-sharing}

Poor communication between healthcare systems hampers and impedes patient follow-up and increases risks of young people disengaging from healthcare or, conversely, care duplication (Perry et al., 2016). Increased utilisation of communication technologies may assist, although many factors outside the direct control of healthcare services may need to be addressed first. A key issue deterring use in regional and rural Australia is internet network coverage, reported by some diabetes educators in non-metropolitan areas as erratic, with inconsistent visual and sound quality (James et al., 2016b).

Ongoing incompatibilities in the electronic medical record data systems used by and between primary, secondary and tertiary care mean missed opportunities to track patient progress and to create large common data sets that could be used to support funding decisions and systematise healthcare service planning (James et al., 2016b; Perry et al., 2016). The risk of patients being lost to follow-up has been highlighted, flagging, at minimum, the need for integration of healthcare records on a mandatory rather than voluntary basis (Perry et al., 2016). Lack of common data systems may be improved through promotion and routine use of accessible secure online health records (Department of Health, 2019).

\section{National quality monitoring}

National monitoring of health outcomes such as type 1 diabetes vascular complications could be used to evaluate the impact of service reconfiguration and/or changes undertaken in service 
delivery. This has been adopted in the United States for many years as part of the Type 1 Diabetes Exchange Clinic Registry (Type 1 Diabetes Exchange, 2017). In Australia, data on National Diabetes Service Scheme registration and usage are stored but without routine linkage to clinical data (Diabetes Australia, 2015b).

National monitoring of complications for key diseases such as diabetes and cancers could be undertaken through coordination of general practice, nationally through structures analogous to the Primary Health Networks of New South Wales. However, this avenue presents challenges as practices are generally private businesses and software systems are often not compatible. The development of disease complications and their progression could, however, be made notifiable as service key performance indicators, on a par with other indicators (Australian Institute of Health and Welfare, 2016). Recent developments such as the collaborative Australasian Diabetes Data Network Registry (Australasian Diabetes Data Network, 2019) will support future reportage. Expansion of the data registry to include adult services has been considered and might encompass existing local registries.

\section{Access to subsidised diabetes-related supplies}

Consideration could also be given to adolescents and young adults' access to blood glucose testing strips, CSII and continuous glucose monitoring consumables. In Australia, these consumables are government-subsidised via the National Diabetes Services Scheme (Diabetes Australia, 2015a). Outside of registration requirements, which necessitate HCP input, there are presently no in-built facilitators or inducements in this scheme to promote regular engagement with diabetes healthcare teams. By contrast, the CSII Assistive Devices Program in Canada (Ontario) requires that people with type 1 diabetes complete a defined number of contacts with a diabetes HCP each year to retain access to provincial government funding for CSII consumables 
(Ontario Ministry of Health and Long-Term Care, 2019). Funding is provided on a yearly

renewable basis and ceases where a renewal form has not been received within one year after the renewal date (Ministry of Health \& Long-Term Care, 2016); this initiative has been associated with positive changes in healthcare utilisation (Liu et al., 2014). Such a program has implications for appropriate service availability, flagging the essential nature of integrated policy and funding models.

\section{DISCUSSION}

This summary of issues in current service provision for adolescents and young adults using type 1 diabetes as an exemplar provides a brief insight into care for a minority patient population with high, complex and long-lasting needs. For many young people, specialist services including secondary disease prevention are inaccessible, not age-relevant, under-utilised or inadequate for purpose. Such issues are not unique either to Australia or to diabetes, but are commonly experienced by young people with long-term conditions; both the issues raised and the opportunities for change are international. Difficulties with metabolic control and provision of healthcare support for adolescents and AYAT1D have, for example, been reported in the United States (American Diabetes Association, 2011; Monaghan et al., 2015). The challenges in bridging two separate health models of care and distinct busy healthcare services has been reported for numerous diseases besides type 1 diabetes (McDonagh \& Viner, 2006), and has been the subject of a paediatric chronic diseases transition framework by the Government of Western Australia (Department of Health Western Australia, 2009). Similarly, actual and potential inequity in healthcare service support has also been reported for young adults with cancer (Birch et al., 2008). 
Policy and practice innovation are required to assist individual clinicians, specialist healthcare services, managers of healthcare organisations and external stakeholders to better support young people, especially outside metropolitan areas. The need for consistent, coordinated and agerelevant care, and the infrastructure to support this, presents an opportunity to drive integration of care and team-working across as well as within disciplines and settings. There is also a need for national standards to support education for young people with long-term conditions, supported by 'centres of reference' that include remote teleconference support for patients and educators. Young adults should be engaged and empowered to be part of change and accountability mechanisms. This could be monitored through rates of acute and preventative healthcare service usage, as well as development and/or progression of disease complications.

Change will likely necessitate investment in health system infrastructure, alongside changes to spending on public health interventions. Development of new funding models to cost-shift to promote expansion of preventive care could be cost neutral or cost-saving (Kiran et al., 2012). Cost effectiveness analyses should be undertaken to support investment, and to determine the level of efficiency and effectiveness of proposed models of care, particularly in view of climates of cost retrenchment worldwide. Data obtained could provide evidence-based information to, in an Australian context, local health districts and the Australian Government; could assist with funding decisions to achieve cost-effective allocation of resources, and maximise benefits for adolescents and young adults with long-term conditions. 
Innovation will likely impact upon the role of nurses, who are key to the education, treatment and support of AYAT1D. In many countries, including Australia, nursing has demonstrated its versatility as an occupation: new roles and career pathways for adequately prepared nurses evolve to meet patients' needs, leading to expanded scopes of nursing practice and responsibilities. Nurses can act as agents for change by making their voices heard, and through use of evidence.

\section{CONCLUSION}

In summary, whilst this discussion does not purport to present either a comprehensive or exhaustive consideration of the issues posed in care of adolescents and young adults, it highlights the wide variety of issues at the bio-psycho-social level of the individual, health services policy and practice that challenge provision of effective health support for adolescents and young adults. Inter-sectoral, multi-level and multi-component opportunities are available to engage and empower young people to be part of change and accountability mechanisms, and to transform the support available and outcomes achievable. A priority research agenda can drive innovation, provide evidence-based information to local, state and national service providers, policy makers and funders, and achieve cost-effective allocation of resources for optimal outcomes. The need for change is pressing. 


\section{REFERENCES}

Agrawal, S., Lakshminarayanan, S., \& Sekhar Kar, S. (2016). Doctor-shopping behavious among diabetic patients in urban Puducherry. Int J Adv Med Health Res, 3(1), 20-26.

Alotaibi, A., Perry, L., Golizedah, L., \& Al Ganmi, A. (2016). Diabetes knowledge of nurses in different countries: An integrative review. Nurse Educ Today, 39, 32-49.

American Diabetes Association. (2011). Diabetes care for emerging adults: recommendations for transition from pediatric to adult diabetes care systems. Diabetes Care, 34, 2477-2485.

Arnett, J. (2004). Emerging adulthood: the winding road from the late teens through the twenties. Oxford University Press: New York.

Australasian Diabetes Data Network. (2019). Research. Available at: http://www.addn.org.au/research/, accessed 10th June 2019.

Australian Communications and Media Authority. (2013). Communications report 2011-12 series. Report 3 - smartphones and tablets. Take-up and use in Australia. Australian Government: Canberra.

Australian Diabetes Educators Association. (2019). Mentoring program. Available at: http://www.adea.com.au/credentialling/mentoring-program/, accessed 10th June 2019.

Australian Institute of Health and Welfare. (2016). KPIs for Australian public mental health services: PI 02J - 28 day readmission rate. Available at: http://meteor.aihw.gov.au/content/index.phtml/itemId/630360, accessed 7th January 2020.

Australian Type 1 Diabetes Guidelines Expert Advisory Group. (2011). National evidence-based clinical care guidelines for type 1 diabetes in children, adolescents and adults. Australian Government: Canberra.

Birch, J., Pang, D., Alston, R., Rowan, S., Geraci, M., Moran, A., \& Eden, T. (2008). Survival from cancer in teenagers and young adults in England 1979 - 2003. Brit J Cancer, 99, 830-855.

Blakemore, S., \& Choudhury, S. (2006). Development of the adolescent brain: implications for executive function and social cognition. J Child Psychol Psyc, 47, 296-312.

Bowden, T., Lang, E., Conwell, L., Kamp, M., \& Cotterill, A. (2009). Sweet Program: Effective transition of young people with diabetes to adult care in Queensland. Australian Diabetes Educators Association: Adelaide Australia.

Campbell, F., Biggs, K., Aldiss, S., O'Neill, P., Clowes, M., Mcdonagh, J., . . Gibson, F. (2016). Transition of care for adolescents from paediatric services to adult health services. CD009794. Cochrane Database Syst Rev.

Danne, T., Lion, S., Madaczy, L., Veeze, H., Raposo, F., Rurik, I., . . Kordonouri, O. (2012). Criteria for Centers of Reference for pediatric diabetes - a European perspective. Pediatr Diabetes, 13(Suppl 16), 62-75.

Department of Health. (2019). My Health Record. Available at: https://www.myhealthrecord.gov.au/for-healthcareprofessionals? gclid=EAIaIQobChMI5MW_gOLd4gIV7LDtCh2bMg7vEAAYASAAEgILU D_BwE, accessed 10th June 2019.

Department of Health Western Australia. (2009). Paediatric chronic diseases transition framework. Department of Health, Western Australia; Perth. 
Diabetes Australia. (2006). Young adults with diabetes: needs analysis. Available at: https://static.diabetesaustralia.com.au/s/fileassets/diabetes-australia/6321f173-164242ed-8501-e95dclffa189.pdf, accessed 10th June 2019.

Diabetes Australia. (2012). Youth transition survey. Diabetes Australia: Canberra.

Diabetes Australia. (2015a). National Diabetes Services Scheme - product and supply. Available at: https://www.ndss.com.au/product-and-supply, accessed 10th June 2019.

Diabetes Australia. (2015b). National Diabetes Services Scheme, Available at: www.ndss.com.au, Accessed on 10th June 2019.

Dunbabin, J., Perry, L., Steinbeck, K., Haas, M., James, S., \& Lowe, J. (2015). Can telehealth engage young people with type 1 diabetes? Experiences from the YOuR-Diabetes project. Aust Diabetes Educ, 18(3), 32-34.

Farrell, K., \& Holmes-Walker, D. (2011). Mobile phone support is associated with reduced ketoacidosis in young adults. Diabet Med, 1001-1004.

Garvey, K., Markowitz, J., \& Laffel, L. (2012). Transition to Adult Care for Youth with Type 1 Diabetes. Curr Diab Rep, 12(5), 533-541.

Giles, J., Visentin, K., \& Phillips, P. (2009). Building and supporting a diabetes education workforce, available at: https://www.ruralhealth.org.au/10thNRHC/10thnrhc.ruralhealth.org.au/papers/docs/Giles Jane_D2.pdf, accessed 7th January 2019.

Government of Western Australia. (2019). Rural link. Available at: https://www.mhc.wa.gov.au/getting-help/helplines/rurallink/, accessed 10th June 2019.

Grunberger, G., Abelseth, J., Bailey, T., Bode, B., Handelsman, Y., Hellman, R., . . Rothermel, C. (2014). Consensus statement by the American Association of Clinical Endocrinologists /American College of Endocrinology Insulin Pump Therapy task force. Endocr Pract, 20(5), 463-489.

Hynes, L., Byrne, M., Dinneen, S., McGuire, B., O’Donnell, M., \& McSharry, J. (2014). Barriers and facilitators associated with attendance at hospital diabetes clinics among young adults (15 - 30 years) with type 1 diabetes mellitus: a systematic review. Pediatr Diabetes, 17(7), 509-518.

James, S. (2017). Current and future services to support young adults with type 1 diabetes in Australia, available at: https://opus.lib.uts.edu.au/handle/10453/120181, accessed 10th June 2019.

James, S., Gallagher, R., Dunbabin, J., \& Perry, L. (2014a). Prevalence of vascular complications and factors predictive of their development in young adults with type 1 diabetes: systematic literature review. BMC Res Notes, 7(593), 1-11.

James, S., Perry, L., Gallagher, R., \& Lowe, J. (2016a). Diabetes Educators' intended and reported use of common diabetes-related technologies: discrepancies and dissonance. $J$ Diab Sci Tech, 10(6), 1277-1286.

James, S., Perry, L., Gallagher, R., \& Lowe, J. (2016b). Diabetes educators: perceived experiences, supports and barriers to use of common diabetes-related technologies. $J$ Diab Sci Tech, 10(5), 1112-1115.

James, S., Perry, L., Gallagher, R., Lowe, J., Dunbabin, J., McElduff, P., . . Steinbeck, K. (2014b). Service usage and vascular complications in young adults with type 1 diabetes. BMC Endoc Disord, 14(39), 1-9. 
Kibbey, K., Speight, J., Wong, L., Smith, L., \& Teede, H. (2013). Diabetes care provision: barriers, enablers and service needs of young adults with type 1 diabetes from a region of social disadvantage. Diabet Med, 30, 878-884.

Kiran, T., Shah, B., Vivtor, J., Glazier, R., \& Kopp, A. (2012). The relationship between financial incentives and quality of diabetes care in Ontario, Canada. Diabetes Care, 35, 1038-1046.

Lane, J., Ferguson, A., Halla, J., McElligott, M., Miller, M., Lane, P., \& Pfeffer, E. (2007). Glycemic control over 3 years in a young adult clinic for patients with type 1 diabetes. Diabetes Res Clin Pract, 78(3), 385-391.

Latham, L., \& Gard Marshall, E. (2015). Performance-based financial incentives for diabetes care: an effective strategy? Can J Diabetes, 39, 83-87.

Liu, S., Shah, B., \& Harris, S. (2014). Provincially funded Insulin Pump Therapy and Healthcare Utilization in Adults with Type 1 Diabetes, Abstract 161. Can J Diabetes, 38(5), s59-s60.

Logan, J., Peralta, E., Brown, K., Moffett, M., Advani, A., \& Leech, N. (2008). Smoothing the transition from paediatric to adult services in type 1 diabetes. J Diabetes Nurs, 12,328 338.

McDonagh, J., \& Viner, R. (2006). Lost in transition? Between paediatric and adult services. BMJ, 332(435), 1-7.

Ministry of Health \& Long-Term Care. (2016). Insulin Pump and Supplies Policy and Administration Manual - Assistive Devices Program, Available at: http://www.health.gov.on.ca/en/pro/programs/adp/policies_procedures_manuals/docs/ins ulin_pump_manual.pdf, Accessed 7th January 2020.

Monaghan, M., Helgeson, V., \& Wiebe, D. (2015). Type 1 Diabetes in Young Adulthood. Curr Diabetes Rev, 11(4), 239-250.

Nakhla, M., Bell, L., \& Wafa, S. (2017). Improving the transition from pediatric to adult diabetes care: the pediatric care provider's perspective in Quebec, Canada. BMJ Open Diab Res Care, 5, 1-7.

New South Wales Agency For Clinical Innovation. (2013). Transition care network for young people with chronic childhood illnesses/disabilities framework. New South Wales Agency For Clinical Innovation: Sydney.

Ng, A., Crowe, T., Ball, K., \& Rasmussen, B. (2017). Transitional Needs of Australian Young Adults With Type 1 Diabetes: Mixed Methods Study. JMIR Diabetes, 2(2), e29.

O'Hara, M., Hynes, L., O'Donnell, M., Nery, N., Byrne, M., Heller, S., \& Dinneen, S. (2017). A systematic review of interventions to improve outcomes for young adults with Type 1 diabetes. Diab Med, 34(6), 753-769.

Ontario Ministry of Health and Long-Term Care. (2019). Assistive devices program. Insulin pump therapy. Available at: www.health.gov.on.ca/en/public/programs/adp/insulin_pamp.aspx, accessed 10th June 2019.

Patton, G., Sawyer, S., Santelli, J., Ross, D., Afifi, R., Allen, N., . . Kakuma, R. (2016). Our future: a Lancet Commission on adolescent health and wellbeing. Lancet, 387(10036), 2423-2478.

Perry, L., James, S., Gallagher, R., Dunbabin, J., Steinbeck, K., \& Lowe, J. (2016). Supporting patients with type 1 diabetes using continuous subcutaneous insulin infusion therapy: difficulties, disconnections and disarray. J Eval Clin Pract, 23(4), 719-724. 
Perry, L., James, S., Steinbeck, K., Dunbabin, J., \& Lowe, J. (2017). Young people with type 1 diabetes: attitudes, perceptions and experiences of diabetes management and continuous subcutaneous insulin infusion therapy. J Eval Clin Pract, 23(3), 554-561.

Perry, L., Lowe, J., Steinbeck, K., \& Dunbabin, J. (2012). Services doing the best they can: service experiences of young adults with type 1 diabetes mellitus in rural Australia. $J$ Clin Nurs, 21, 1955-1963.

Perry, L., Steinbeck, K., Dunbabin, J., \& Lowe, J. (2010). Lost in transition? Access to and uptake of adult health services and outcomes for young people with type 1 diabetes in regional New South Wales. Med J Aust, 193(8), 444-449.

Pomerantz, J., \& Brooks, D. (2017). ECAR Study of Undergraduate Students and Information Technology, EDUCAUSE Center for Analysis and Research. Research report. Louisville: ECAR.

Redberg, R. (2014). Hospital admissions for hypoglycemia now exceed those for hyperglycemia in Medicare beneficiaries. JAMA Intern Med, 174(7), 1125-1130.

Sequeira, P., Pyatak, E., Weigensberg, M., Vigen, C., Wood, J., Ruelas, V., . . Peters, A. (2015). Let's empower and prepare (LEAP): evaluation of a structured transition program for young adults with type 1 diabetes. Diabetes Care, 38(8), 1412-1419.

The Australian National Adult Insulin Pump Therapy Working Group. (2013). Provision of quality care for adults with type 1 diabetes requiring insulin pump therapy (IPT). Infosyst Asia, 8(1), 1-12.

Type 1 Diabetes Exchange. (2017). T1D Exchange Registry. Available at: https://tldexchange.org/research/registry/, accessed 7th January 2020.

United Nations Human Rights. (2019). CHR call for submissions on its General Comment on the rights of adolescents, Available at: http://www.ohchr.org/EN/HRBodies/CRC/Pages/CallRightsofAdolescents.aspx, accessed 3rd November 2019.

Victorian Government. (2018). Nurse-on-call. Available at: https://www2.health.vic.gov.au/primary-and-community-health/primary-care/nurse-oncall, accessed 10th June 2019.

This article is protected by copyright. All rights reserved. 


\section{University Library}

\section{- M I I N E R VA \\ A gateway to Melbourne's research publications}

Minerva Access is the Institutional Repository of The University of Melbourne

Author/s:

James, S;Perry, L;Gallagher, R;Lowe, J

Title:

A discussion of healthcare support for adolescents and young adults with long-term conditions: Current policy and practice and future opportunities

Date:

2020-08-18

\section{Citation:}

James, S., Perry, L., Gallagher, R. \& Lowe, J. (2020). A discussion of healthcare support for adolescents and young adults with long-term conditions: Current policy and practice and future opportunities. INTERNATIONAL JOURNAL OF NURSING PRACTICE, 26 (5), https:// doi.org/10.1111/ijn. 12882.

Persistent Link:

http://hdl.handle.net/11343/276159 